\title{
Using the Community of Inquiry Framework to Scaffold Online Tutoring
}

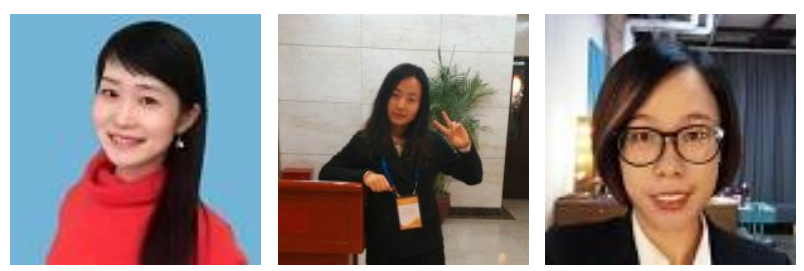

Xiaoying Feng, Jingjing Xie, and Yue Liu

Beijing Normal University

\begin{abstract}
Tutoring involves providing learners with a suitable level of structure and guidance to support their learning. This study reports on an exploration of how to design such structure and guidance (i.e., learning scaffolds) in the Chinese online educational context, and in so doing, answer the following two questions: (a) What scaffolding strategies are needed to design online tutoring, and (b) How should different levels of scaffolding intensity be emphasized in different stages of online tutoring in such educational contexts? A model for online tutoring using the Community of Inquiry framework was developed and implemented in this study. It focused attention on both the critical role of the tutor in online learning and the importance of scaffolding in online tutoring. Both qualitative and quantitative methods were used to collect data, including questionnaires, interviews, and content analysis. In considering the variation of scaffolding throughout the online course, results showed that: (a) As long as a high degree of social presence is established in the initial phase, scaffolds for social presence can be withdrawn gradually throughout the course; (b) High-intensity teaching presence is much more important in the mid-phase of the course than in other phases; (c) "Discourse facilitation" should be emphasized for teaching presence in the mid-phase, while "direct instruction" scaffolding is needed in the last phase; and (d) The greatest need for scaffolding of cognitive presence occurs in the final phase of the course.
\end{abstract}

Keywords: online tutoring, online presence, scaffolding, community of inquiry

\section{Introduction}

In an online learning environment, effective conversations, interactions and collaborations play an 
important role in increasing students' involvement, engagement, achievement and satisfaction in the learning process (Garrison, Anderson, \& Archer, 2003; Laurillard, 2002; McConnell, 1994). However, it is widely recognized that merely forming a discussion group and providing the technology for it to function will not lead to learning (Guldberg \& Pilkington, 2007). The role of the tutor in moderating and supporting the discussion is critical (Barker, 2002; Berge, 1995; Denis, Watland, Pirotte, \& Verday, 2004; Salmon, 2003). Generally, online tutoring refers to the academic support provided by tutors to students in an online course (Simpson, 2002). But online tutoring is much more than that. The online tutors/e-tutors are the new generation of teachers for the contemporary learning context who work with learners online and who take care of online learning and its various aspects as a whole (Goga, 2012; Salmon, 2004).

The role of the tutor (or moderator) is critical in an online learning environment (Chism, 1998; Schindler \& Burkholder, 2014). Effective interaction or collaboration would not naturally happen without skillful support and moderation by tutors (Anderson, 2008; Guldberg \& Pilkington, 2007; Rourke \& Anderson, 2002). However, too much control of discussion by tutors can also run the risk of constraining participation (Maddix, 2012; Mercer, 1995; Pilkington \& Walker, 2003). So the challenge for the online tutor/moderator is to know when and how much to support and moderate, and when to withdraw.

There are many different roles and competencies required of online tutors (Bennett \& Marsh, 2002; Berge, 1995). These include being more than a mere transmitter of knowledge; instead, the online tutor should be a facilitator and supporter of learning (Denis et al., 2004; Lentell, 2003; Pilkington \& Walker, 2003). Roles of the online tutor also include contributing specialist knowledge and insight, encouraging students to participate, nurturing friendly and constructive collaboration, organizing activities around threaded discussions, helping participants build relationships, and providing feedback and assessment (Barker, 2002; Garrison, Anderson, \& Archer, 2001; Lentell, 2003; Ryan \& Deci, 2000; Salmon, 2004). There have been attempts to structure these activities into four types of roles for online tutoring. These comprise a social, an organizational, a pedagogical and a technical role (Berge, 1995; Daele \& Docq, 2002).

Obviously, as a facilitator of online learning, the online tutor's key responsibility is to scaffold the online learning experience of students, which is challenging in the best of circumstances. In the Chinese educational context, the online tutor is faced with additional serious challenges in the conduct of this role. Online courses in China generally adopt a predominantly content-focused approach to teaching and learning where teachers are expected to know everything and teach students directly. And Chinese students expect to learn from their teachers, but not from their peers. These expectations of Chinese teachers and the behavior of Chinese students pose serious obstacles to promoting any kind of collaborative and peer-group based learning activities in online educational settings. Most of the online teachers and students in China wouldn't know how to carry out such collaborative learning activities even if they wanted to do so. Online tutors and teachers in the Chinese educational context need help with how to scaffold online students' learning and provide the right amount of structure and guidance while doing so. 


\section{Purpose of this Study}

The study reported in this paper sought to address this deficit in the Chinese online educational context. It set about to investigate how to better design online tutoring in the Chinese educational context and answer the following two questions: (a) What scaffolding strategies are needed to design better online tutoring? and (b) How should different levels of scaffolding intensity be emphasized in different stages of online tutoring?

As part of this study, a model for online tutoring using the CoI (Community of Inquiry) framework was developed. It was expected that this model would help the Chinese instructor/tutor/teacher design their online tutoring and give improved support for Chinese online learners to enable them to meet their online learning needs.

This study reports on the first cycle of a design-based approach as part of this initiative. It adopted Reeves' widely known four phases of a design-based approach (Reeves, 2006) as a guiding framework. These phases are:

1. Analysis of practical problems.

2. Development of solutions.

3. Implementation and testing of solutions.

4. Reflection and refinement.

\section{The Community of Inquiry Framework}

The Community of Inquiry (CoI) Model has been widely promoted in online education ever since Garrison, Anderson and Archer proposed it (see Anderson, 2008). The model suggests that deep and meaningful learning results when there is evidence of sufficient levels of the various component "presences" of the approach (i.e., teaching, social, and cognitive presence).

Social presence is defined as the extent to which a student's true self is projected and perceived in an online course (Rourke, Anderson, Garrison, \& Archer, 2001). This has been widely measured in three dimensions, namely: group cohesion, open communication, emotional expression (Garrison, Anderson, \& Archer, 2000). Getting and being ready for this kind engagement depends upon being able to work the tools of the online learning environment. Helping students with their technical problems is an important part of online tutoring (Anderson, 2008; Berge, 1995; Denis, 2003). In fact, it has been argued that the first step in online tutoring involves helping new students become familiar with the online setting by learning how to use the course software (Salmon, 2002). Hence, in this model, a fourth type of scaffold is proposed as part of social presence (i.e., environment acclimation scaffold).

Teaching presence is the direct and indirect role and influence of the tutor and perhaps senior 
students in the design, direction and facilitation of a learning experience (Anderson, Rourke, Garrison, \& Archer, 2001). Teaching presence is seen as a significant determinant of student satisfaction, perceived learning and sense of community (Garrison \& Arbaugh, 2007). In alignment with the definition, the CoI coding template defines three dimensions of teaching presence. These are: instructional management, building understanding, and direct instruction. As it has been found difficult to distinguish between the three dimensions of teaching presence, the dimensions as redefined by Garrison and Anderson, namely: design \& organization, facilitating discourse, direct instruction (Anderson, 2008; Garrison et al, 2010; Garrison \& Arbaugh, 2007), were adopted as the bases for three types of scaffold for teaching presence in this model.

Cognitive presence is taken to mean the extent to which the students are able to construct meaning through sustained communication (Garrison, Anderson, \& Archer, 2000). As a developmental model of the CoI framework, the Practical Inquiry (PI) model was introduced into the framework (Garrison, Anderson \& Archer, 2001). Four phases of critical inquiry are identified: triggering event, exploration, integration, and resolution. The four phases of the PI model have been used widely as indicators to measure cognitive presence ever since. When designing scaffolds for cognitive presence, scaffolds for "triggering event" may happen at the "instructional design \& organization" part of teaching presence; hence, in this study, only the last 3 phases are adopted for cognitive presence, which are exploration scaffold, integration scaffold, and resolution scaffold.

Existing research has underscored the importance of teaching presence and cognitive presence, and has established that teaching presence has a significant effect on both social presence and cognitive presence (Garrison, 2011; Garrison, Anderson, \& Archer, 2010; Joo, Lim, \& Kim, 2011; Shea \& Bidjerano, 2009; Szeto, 2015). Teaching presence and cognitive presence are also reported to have positive effects on learner satisfaction, which is a predictor of student persistence (Joo et al., 2011; Lee, 2014).

But studies on the significance of social presence have presented contradictory results. Some studies have reported that social presence is not a significant predictor of satisfaction (Joo et al., 2011; Ke, 2010; Shea \& Bidjerano, 2009). Other researchers suggest that social presence is an important mediating variable between teaching and cognitive presence, as well as a predictor of learning satisfaction (Annand, 2011; Garrison, 2003; Garrison et al., 2010; Tu \& McIsaac, 2002). However, it has been argued that it is not cognitive density but collaborative learning and interaction that is related to the quality of learning. Therefore, "the higher the social presence, the better the quality of cognitive presence" (Lee, 2014).

Strategies for enhancing teaching presence include assigning a role to students, giving encouraging information, asking thought-provoking questions, keeping dialogs on track, deciding on the effective group size, and providing rubrics such as clear communication protocols and requirements for participation (Anderson, 2008; Branon \& Essex, 2001; Dennis \& Williams, 2005; Schellens, Van Keer \& Valcke, 2005; Schindler \& Burkholder, 2014; Wishart \& Guy, 2009). Garrison has argued nevertheless that the instructor should not only create teaching presence but also create cognitive presence and mediate social presence to optimize the learning environment (Garrison et al., 2010). 


\section{Using Col to Scaffold Online Tutoring}

As described above, the CoI framework provides a conceptual model for defining, describing and measuring elements supporting the development of online learning communities (Garrison et al., 2010; Swan \& Ice, 2010). The existence of the three principal types of presence-social presence, teaching presence and cognitive presence-was first validated by the development and measurement of a set of indicators, as shown in Table 1 (see Garrison et al., 2000).

Table 1

Community of Inquiry Coding Template

\begin{tabular}{lll}
\hline Elements & Categories & Indicators (examples only) \\
\hline Cognitive & Triggering Event & Sense of puzzlement \\
Presence & Exploration & Information exchange \\
& Integration & Connect ideas \\
& Resolution & Apply new idea \\
Social Presence & Emotional Expression & Emotions \\
& Open Communication & Risk-free expression \\
& Group Cohesion & Encourage collaboration \\
Teaching & Instructional Management & Defining and initiating discussion \\
Presence & & topics \\
& Building Understanding & Sharing personal meaning \\
& Direct Instruction & Focusing discussion \\
\hline
\end{tabular}

Scaffolding is any form of instructional support that enables students to complete tasks they would be unable to master without assistance (Schindler \& Burkholder, 2014). Salmon's "Five-stage Model of Teaching and Learning Online" (Salmon, 2004) offers some help on how one might approach online moderation in order to build a sense of community. Each stage in the model calls for different e-moderating skills. Salmon considers her model as a scaffold for a structured and paced program of e-learning (Salmon, 2004).

An important feature of scaffolding is the variation of its intensity-scaffolding should be provided when needed and faded gradually when students achieve their goals and targets. Some have also argued that the intensity of scaffolds should be adaptive rather than fixed (Azevedo, 2005; Dillenbourg, 2002; Feng, 2012).

In this study, teaching, social, and cognitive presence are adopted as the targets of design of scaffolds for online tutoring. The types of scaffold are identified according to dimensions of teaching, social, and cognitive presence. Table 2 presents the model of scaffold design for online tutoring in this study as well as typical strategies for each type of scaffold (see Table 2). 
Table 2

Scaffold Design for Online Tutoring

\begin{tabular}{|c|c|c|}
\hline Target & Scaffold & Typical strategies (examples) \\
\hline \multirow{4}{*}{$\begin{array}{l}\text { Social } \\
\text { Presence }\end{array}$} & Group Cohesion Scaffold & Welcome letter; Ice-breaking activity \\
\hline & Emotional Expression Scaffold & $\begin{array}{l}\text { Posting the outstanding student list and } \\
\text { their contribution }\end{array}$ \\
\hline & Open Communication Scaffold & $\begin{array}{l}\text { Calling the names of students kindly; } \\
\text { Publishing online discussion etiquette }\end{array}$ \\
\hline & $\begin{array}{l}\text { Environment Acclimation } \\
\text { Scaffold }\end{array}$ & $\begin{array}{l}\text { Informing the process of problem solving } \\
\text { and efforts }\end{array}$ \\
\hline \multirow[t]{3}{*}{$\begin{array}{l}\text { Teaching } \\
\text { Presence }\end{array}$} & Design \& Organization Scaffold & $\begin{array}{l}\text { Releasing a task checklist weekly; } \\
\text { Using internet messaging and e-mail to } \\
\text { alert courses process }\end{array}$ \\
\hline & Discourse Facilitation Scaffold & $\begin{array}{l}\text { Sharing ones learning experiences; } \\
\text { Focusing discussion on relevant issues }\end{array}$ \\
\hline & Direct Instruction Scaffold & $\begin{array}{l}\text { Explaining the links between learning } \\
\text { activities and learning objectives }\end{array}$ \\
\hline \multirow{3}{*}{$\begin{array}{l}\text { Cognitiv } \\
\text { e } \\
\text { Presence }\end{array}$} & Exploration Scaffold & $\begin{array}{l}\text { Providing cases; Guiding students to } \\
\text { think combining their own practice }\end{array}$ \\
\hline & Integration Scaffold & $\begin{array}{l}\text { Reflecting on learning every } \\
\text { weekend/end of each module }\end{array}$ \\
\hline & Resolution Scaffold & $\begin{array}{l}\text { Debating; Sharing practical cases that are } \\
\text { related to the courses }\end{array}$ \\
\hline
\end{tabular}

We hypothesize that the intensity of scaffolds for teaching, social and cognitive presence should be different and varied during the course of online tutoring. Figure 1 represents the intensity of scaffold design for the three types of presence in this study in the three phases of the course-i.e., the initial phase, mid-phase, final phase.

- In the initial phase of the course, scaffold design should be of highest intensity for SP (Social Presence), higher intensity for TP (Teaching Presence), and of less intensity for CP (Cognitive Presence).

- In the mid-phase of the course, scaffold design should be of strongest intensity for TP, stronger intensity for $\mathrm{CP}$, and less intensity for SP.

- In the final phase, CP should be emphasized, with less scaffolding for TP and less for SP. 


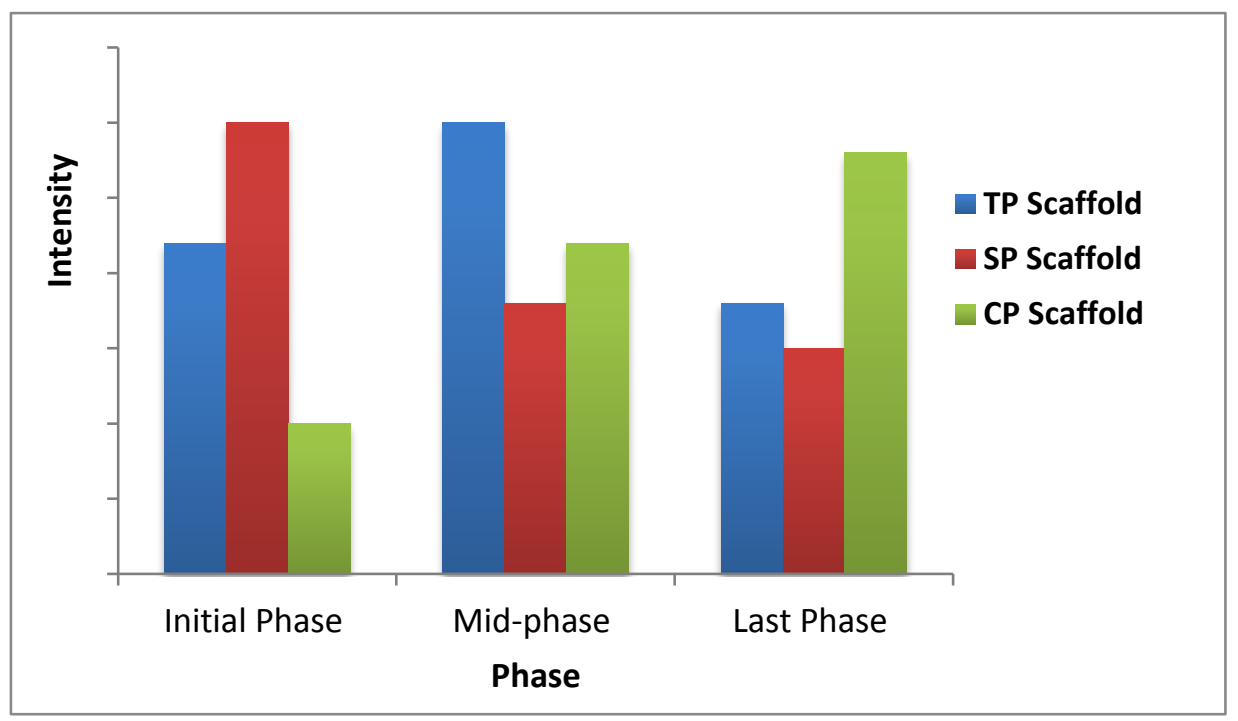

Figure 1. Scaffold intensity design in different phases of a course (adapted from Salmon, 2004).

\section{Implementing and Testing of Solutions}

\section{Context}

The designed scaffolds for online tutoring (see Table 2) were implemented in an online training course for practitioners in open and distance educational institutions in China, delivered over the summer of 2015. The course included 6 modules and lasted 10 weeks. The first 2 weeks (Module 1) comprised the initial phase, week 3 to week 8 (Modules 2-5) the mid-phase, and week 9 to week 10 (Module 6) comprised the final phase.

\section{Participants}

Participants in this study, 30 in total, were all on-the-job practitioners, senior teachers from open universities in China, with an average of 13 years of working experience in the field of distance education. The average age of the group was 38. All students were of Chinese ethnic origin. There were 8 male participants and 22 females.

\section{Design of the Course}

The course was offered totally online, with 3 video conferences over the 10-week study. There was no final exam in the course. The students were required to watch or read at least $80 \%$ of the online resources, to engage in at least 2 online discussion activities and to post at least 1 message in the online forum in each module. Except for the self-study of online resources such as videos, all the teaching and learning interaction happened in the online forum. One instructor was in charge of the online discussion and tutoring. Both the instructor and students engaged in the discussion with their real names. The students were asked to upload their latest picture and complete a detailed 
self-introduction in the forum in the first week of the course, so as to show their "real self" to classmates.

The course included both individual and collaborative learning activities. Three kinds of collaboration tasks were assigned, as shown in Table 3. And students were encouraged to self-select themselves into a 5 -person group. At the end of the course, each group was required to submit a product about online course design. However, except for the group task assignments, the instructor offered no more intervention or scaffolds on group collaboration.

Table 3

Individual and Collaborative Learning Activities

\begin{tabular}{|c|c|}
\hline Individual learning & Collaborative learning \\
\hline . Discussion & - $\quad$ Peer evaluation in Module 4 and Module 5 \\
\hline Debate & - A group summary at the end of each module \\
\hline Reflection & - A group product at the end of the course \\
\hline - Case analysis & \\
\hline$\cdot \quad \ldots$ & \\
\hline
\end{tabular}

Online tutoring was designed and delivered carefully, based on the model presented in Table 2, in order to scaffold the development of presences. Different scaffolding strategies were emphasized in different stages. Table 4 demonstrates the number of strategies used in each phase. Some strategies were used more than once. Not all of these strategies were designed ahead of time; some were adopted during the course of online tutoring. For example, the tutor added an "online debate" strategy in Module 2, when she observed different opinions between students.

Table 4

Average Number of Scaffolding Strategies Used in Different Phases

\begin{tabular}{llll}
\hline Type of presence & \multicolumn{3}{l}{ Number of strategies used for every presence } \\
\cline { 2 - 4 } & Initial phase & Mid-phase* & Last-phase \\
Social Presence & 10 & 8 & 4 \\
Teaching & 12 & 14 & 5 \\
$\begin{array}{l}\text { Presence } \\
\begin{array}{l}\text { Cognitive } \\
\text { Presence }\end{array}\end{array}$ & 1 & 5 & 6
\end{tabular}

* Since the mid-phase included 4 modules, this table shows the average number of strategies in each module in mid-phase. 


\section{Method}

A design-based research approach to research was adopted in this study. Design-based research (DBR) as a concept evolved around the beginning of the $21^{\text {st }}$ century as a practical research methodology that could effectively bridge the chasm between educational research and real-world problems (Amiel \& Reeves, 2008; Anderson \& Shattuck, 2012). It is defined as a systematic but flexible methodology aimed at improving educational practice through iterative analysis, design, development, and implementation, based on collaboration among researchers and practitioners in real-world settings, and leading to contextually-sensitive design principles and theories (Wang \& Hannafin, 2005).

This paper reports the first iteration of our approach to DBR. Both quantitative and qualitative data were collected using surveys, content analysis, and interviews, with the goal to evaluate the solutions in practice, and with the following research questions:

1. What kinds and levels of presence do tutors and students exhibit during the initial phase, mid-phase, and last phase of the course?

2. How do the scaffolds support the development of social, teaching and cognitive presence?

Content analysis was conducted for the first research question. In order to explore the tutor and students' presences, all messages posted in the discussion forum were collected and analyzed. There were a total of 447 posts by students and 76 posts by the tutor. Two researchers analyzed the messages following a coding approach adapted from Shea's framework (Shea, Hayes, Vickers, Gozza-Cohen, Uzuner, Mehta, Valchova, \& Rangan, 2010). In Shea's framework, the Practical Inquiry Model was used for analyzing cognitive presence of students. Although a scaffold for Triggering Event was not included in the design model for online tutoring as shown in Table 2, we still followed the Practical Inquiry Model by identifying the four degrees of cognitive presence of the students, since we took for granted that as the initial stage of cognitive presence, a Triggering Event might be achieved without a special scaffold. Inter-rater reliability between our two researchers was measured using Cohen's Kappa, as shown in Table 5. After negotiation, the inter-rater reliability increased significantly.

Table 5

Inter-rater Reliability Measures: Cohen's Kappa

\begin{tabular}{lll}
\hline Module & Initial Kappa & Negotiated Kappa \\
\hline Module 1 & .570 & .907 \\
Module 2 & .804 & .937 \\
Module 3 & .620 & .932 \\
Module 4 & .731 & .954 \\
Module 5 & .665 & .911 \\
Module 6 & .619 & .798 \\
\hline
\end{tabular}

A survey and interviews were conducted to search for answers to our second research question. The 
survey was conducted at the end of the semester to explore students' perceptions of how the scaffolds supported the development of various forms of presences. All 49 scaffolding strategies designed in the course were listed as items in the questionnaire (see Appendix A) and students were asked to evaluate the impacts of each strategy item on a Likert scale ranging from "very effective", "effective", "so-so", "ineffective" to "very ineffective". Since all the students were of Chinese ethnic origin, the survey was designed in Mandarin. Five experts were invited to ascertain the validity of the questionnaire, and some minor revisions were made to it afterwards. Twenty-six valid completed questionnaires were collected, giving us a return rate of $86.7 \%$. Cronbach's Alpha for items in the survey was 0.901 for social presence, 0.854 for teaching presence, and 0.873 for cognitive presence.

Fifteen students were interviewed in the middle and at the end of the course as part the qualitative data gathering process. The interview questions focused on how the students saw the strategies in supporting the development of social, teaching and cognitive presence in the course. Since most of students lived far away, most of them were interviewed via synchronous online audio meetings.

\section{Results}

Research question 1: What kinds and levels of presence do tutors and students exhibit during the initial phase, mid-phase, and last phase of the course?

Figure 2 presents the tutor's social and teaching presence in each module. The tutor's social and teaching presence was expected to follow our scaffolding intensity design. The figure shows that the tutor exhibited a high level of social and teaching presence in Module 1, which declined gradually with subsequent modules, as we had designed and expected that it would. Although the tutor exhibited a fairly high degree of teaching presence, the content analysis results show that the tutor's teaching presence didn't reach the peak value in the mid-phase, as designed and expected. Some of this behavior may have been influenced by the tutor's personal teaching style.

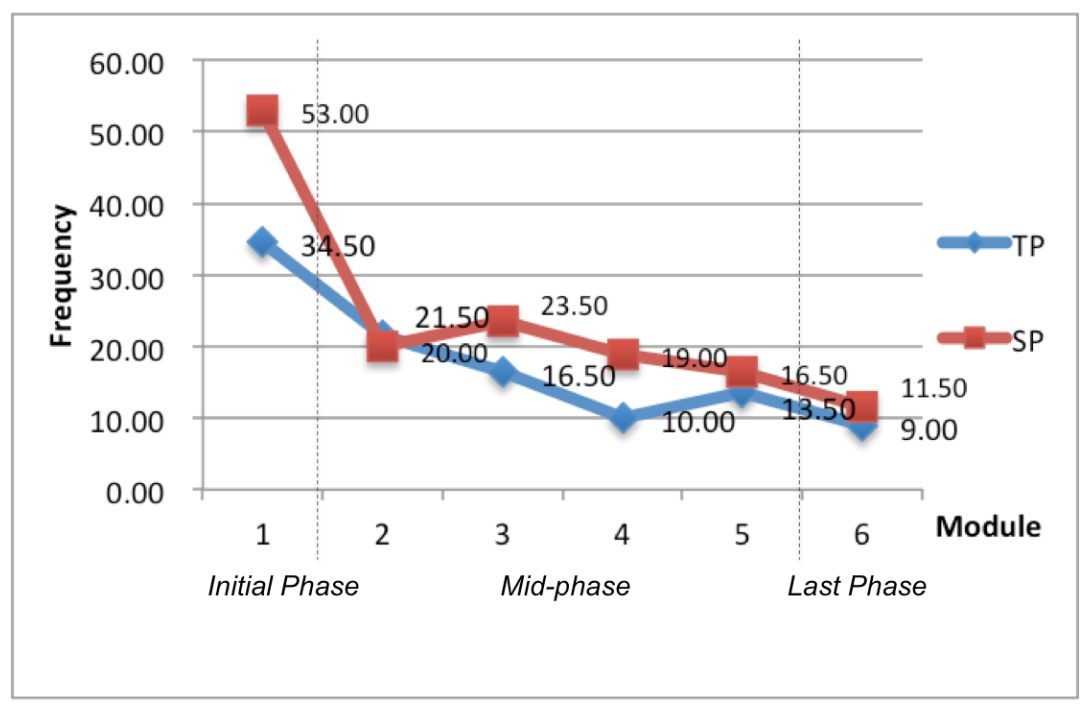

Figure 2. Tutor's social and teaching presence in each module. 
Content analysis results show that students' social presence and cognitive presence were fairly satisfactory, as we had expected (see Figure 3). In the initial phase, the students' social presence was higher than the teaching and cognitive presences, and their cognitive presence was higher than their teaching presence. This result is consistent with the design of the scaffolds. However, the students' social presence did not decline over time as we had expected. In fact, it continued to increase, reaching a peak in the final phase, which suggesting that the withdrawal of scaffolding from Module 2 onwards had no effect on the students' social presence. The students' cognitive presence started from 2.92 posts in the initial phase to a peak of 3.71 in the final phase. The variation in cognitive presence is essentially in agreement with the scaffold intensity for cognitive presence that we designed. The students' behavior in relation to their teaching presence is low. But this is not surprising, as Chinese students are known to demonstrate a rather passive disposition when it comes to assuming a teaching role (Junus, Sadita, \& Suhartanto, 2014; Zhang \& Yao, 2013). The students' social, teaching and cognitive presence all dropped to a low in Module 4.

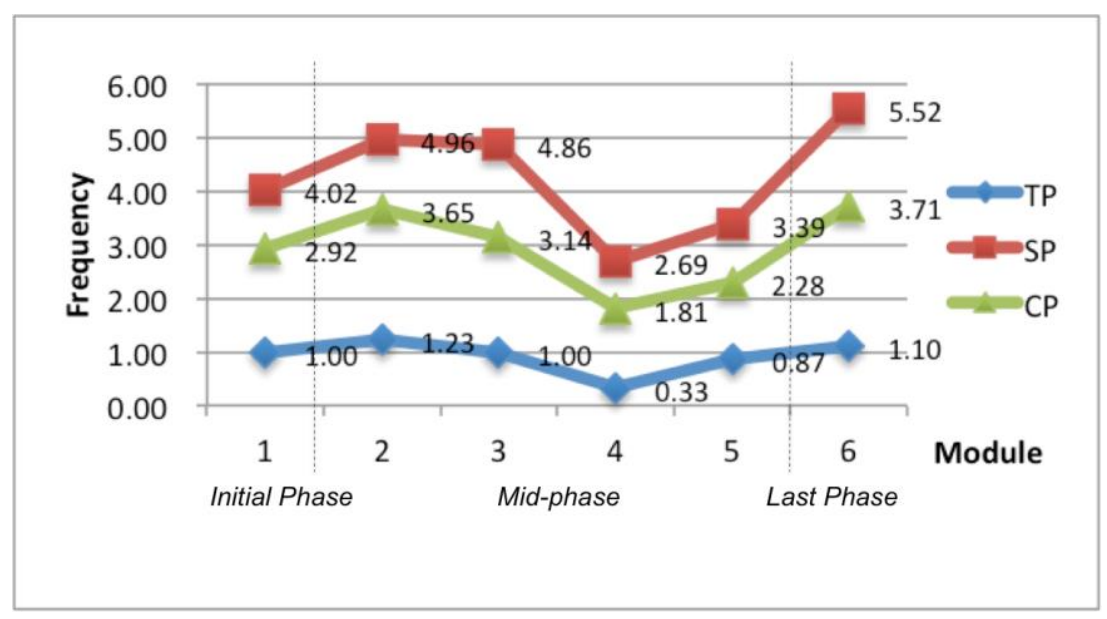

Figure 3. Average number of student's social, teaching and cognitive presence posts in each module.

A closer examination of students' cognitive presence is shown in Figure 4. The Exploration (EX) dimension of cognitive presence was the highest, followed by the Integration (IN) dimension. Dimensions of Resolution (RE) and Triggering Event (TE) were low. The fact that no special scaffolds were designed for Triggering Event in the first iteration might result in the low value of triggering event. Resolution as a dimension of cognitive presence remained low throughout. 


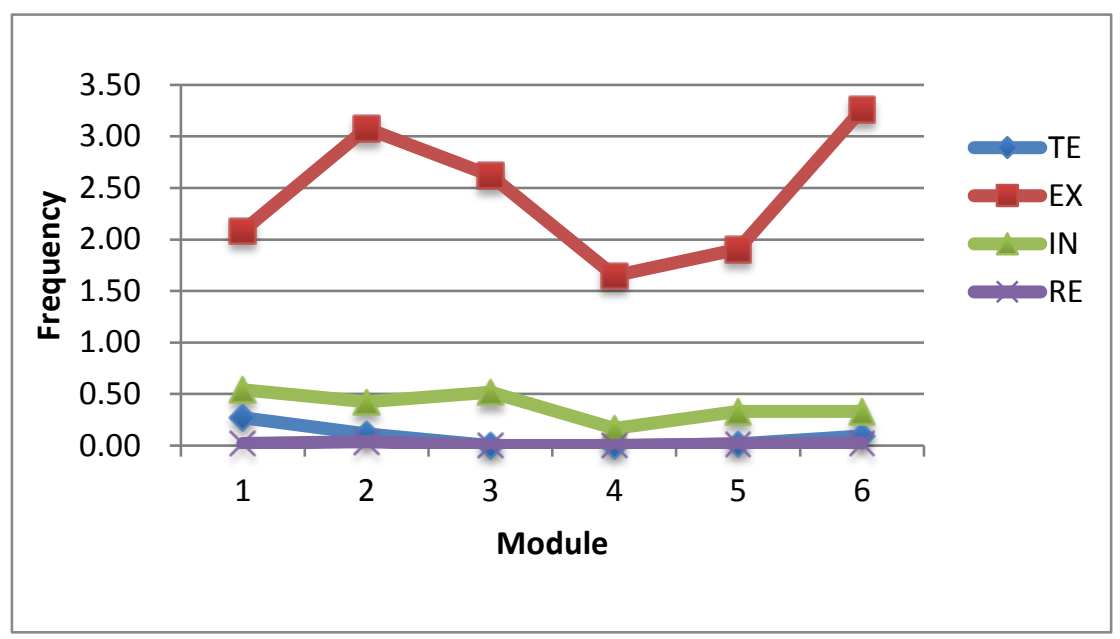

Figure 4. Average number and category of students' cognitive presence posts in each module.

Figure 5 shows a closer examination of students' social presence level. In each module, the value of Emotional Expression (AF) was the highest, followed by Open Communication (OC) and lastly Group Cohesion $(\mathrm{CH})$. This result was consistent with the results of survey and interviews, as shown later.

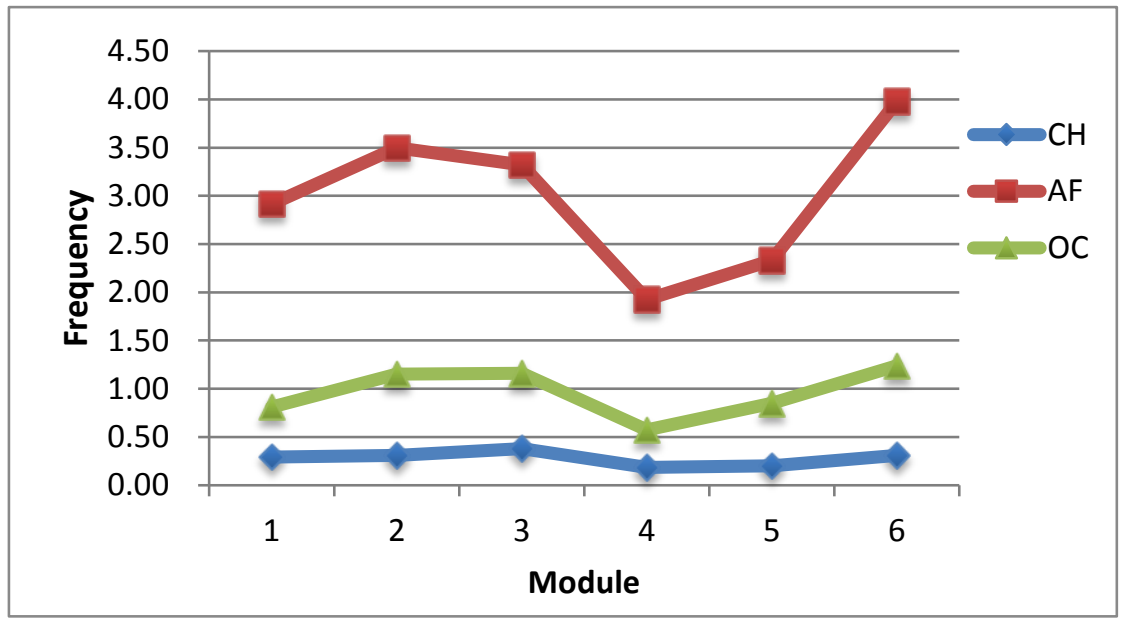

Figure 5. Average number and category of students' social presence posts in each module.

A closer examination of the tutor's teaching presence is presented in Figure 6. In general, the value of Design \& Organization (DE) remains smooth and steady throughout the course. The value of Discourse Facilitation (FD) was highest, indicating that the tutor put the greatest effort into facilitating discourses. This result is consistent with interview data in which students expressed greatest satisfaction with the tutor's "guiding" and "facilitating." The tutor also devoted a lot of time to Direct Instruction (DI), which also kept a high value all throughout until the Final Phase. 


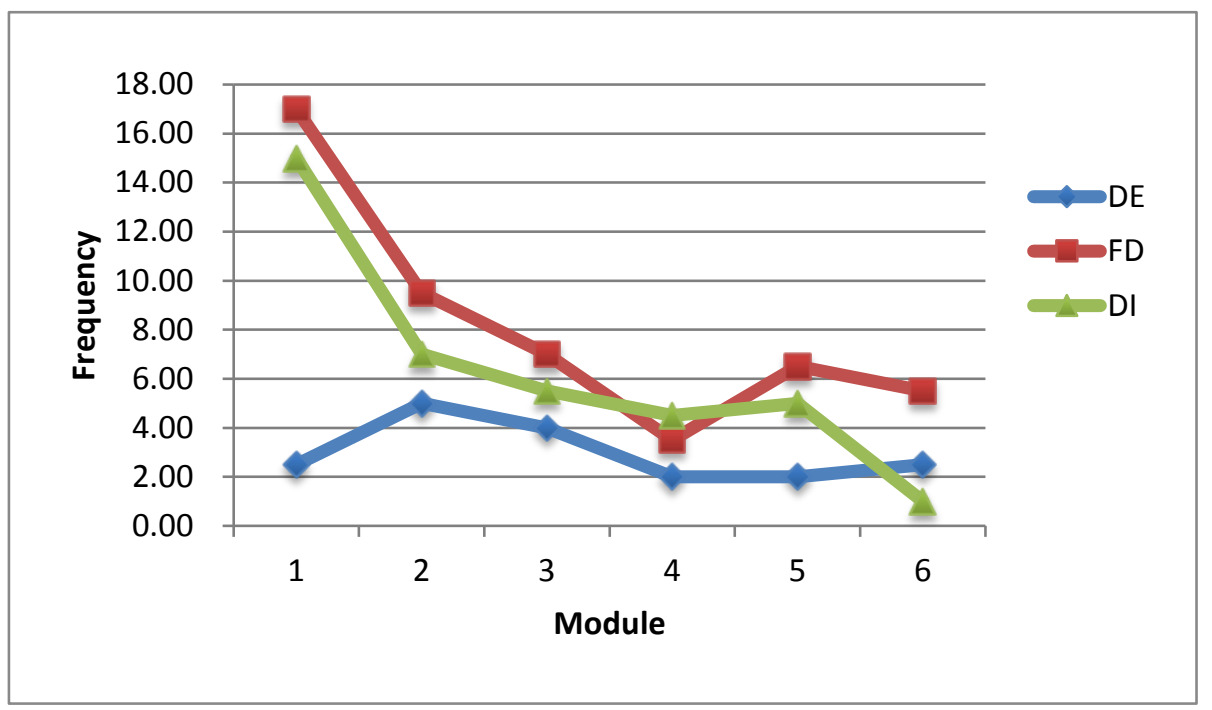

Figure 6. Tutor's teaching presence in each module.

Research question 2: How do the scaffolds support the development of e-presences?

The numbers of strategies implemented as part of the three types of scaffolds were 14,22 , and 13 . The survey results showed that the means of the students' appreciation of the three kinds of scaffolds are all above 4.3, and the standard deviations are below 0.9, suggesting that students had high appreciation of the scaffolding strategies. Students placed highest value on the scaffolds for teaching presence.

Table 6

Survey Results on Effectiveness of Scaffolds for SP, TP, and CP

$\begin{array}{llll}\text { Scaffold type } & \begin{array}{l}\text { Numbers of } \\ \text { Scaffolds }\end{array} & \text { Means } & \text { Std. Error }\end{array}$

\begin{tabular}{llll}
\hline Scaffolds for Social Presence & 14 & 4.31 & .800 \\
Scaffolds for Teaching Presence & 22 & 4.49 & .641 \\
Scaffolds for Cognitive Presence & 13 & 4.38 & .627 \\
\hline
\end{tabular}

\section{Scaffolds for Social Presence}

All four kinds of scaffolds for social presence were considered effective (all means are more than 4.2, and the standard deviations are less than 1.0) (see Table 7). Students placed highest value on Environment Acclimation Scaffolds (M=4.42), which supports Salmon's finding that it's important to help new students become familiar with the online setting early on in the course (Salmon, 2002, 2004). This result is consistent with results on students' social presence derived from content analysis (as shown in Figure 5), in which the environment acclimation dimension has the highest value, followed by group cohesion, emotional expression and open communication. 
Table 7

Survey Results on Effectiveness of Scaffolds for Social Presence

\begin{tabular}{l|l|l|l}
\hline Scaffold type & Scaffolds & Means & Std. Error \\
\hline \multirow{3}{*}{ Scaffolds for SP } & Group Cohesion Scaffolds & 4.28 & .986 \\
& Emotional Expression Scaffolds & 4.28 & .734 \\
& Open Communication Scaffolds & 4.28 & .682 \\
& Environment Acclimation Scaffolds & 4.42 & .611 \\
\hline
\end{tabular}

Table 8 presents the most effective strategies for social presence. Typical strategies, such as "welcome letter," "ice breaking," "team building," and "establishing discussion rules," were considered important and helpful for building a high degree of social presence in the initial phase. These findings are consistent with existing literature on the value of these strategies in online learning support (see Anderson, 2008; Dixon, Crooks, \& Henry, 2006; Salmon, 2004). Another helpful scaffolding strategy in the initial phase was "Establishing rules of etiquette for online discussion." In interviews, students confirmed their appreciation of such efforts to build social presence, suggesting these strategies "let me feel that it's also possible to build an atmosphere or culture of class in an online course." Students also emphasized the importance of emotional support strategies, which was consistent with the survey results. Some students said that "'emotional support' is an effective way to stimulate learner motivation in distance learning," and others expressed that they felt "the tutor was always concerning me and she knew my existence, even though I did not behave actively enough."

Table 8

Most Effective Strategies for Social Presence

\begin{tabular}{|c|c|c|}
\hline Scaffold strategy & Mean & Std. Er. \\
\hline Welcome letter & 4.69 & .855 \\
\hline Online ice-breaking & 4.54 & .877 \\
\hline Use the names of students in a kindly manner when posting. & 4.32 & .646 \\
\hline $\begin{array}{l}\text { Use friendly language, emotional words (respect, apologies, happy, } \\
\text { etc.), humorous utterances, graphic symbols, network language and } \\
\text { so on. }\end{array}$ & 4.55 & .596 \\
\hline Thank students for their contributions, sharing and suggestions. & 4.52 & .593 \\
\hline $\begin{array}{l}\text { Weekly appreciation/weekly star, post the outstanding student list } \\
\text { and their contribution. }\end{array}$ & 4.57 & .590 \\
\hline Get familiar with the course platform. & 4.22 & .518 \\
\hline
\end{tabular}

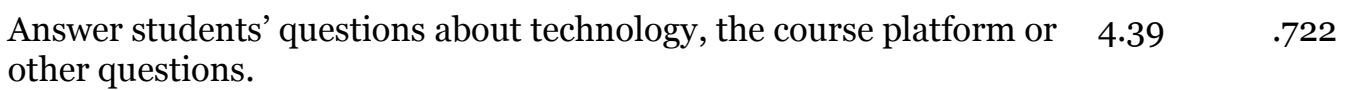

Inform the students about the process of problem solving and their $\quad 4.64 \quad .492$ efforts

Both in the survey result and the content analysis result, the value of "group cohesion" and students' perception of "group cohesion scaffolds" are the lowest. In the interview, students explained that this 
was because there were no clear and specific responsibilities assigned to group members, and they did not contribute much to group work afterwards. Although students highly recognized the "environment acclimation scaffold" in the survey, the interview data shows that students were not satisfied with the support provided, especially in the first several weeks of the course.

\section{Scaffolds for Teaching Presence}

As table 9 shows, three dimensions of scaffolds are perceived to be fairly effective in the development of teaching presence. All of the means are higher than 4.3, and standard deviations are lower than 0.8 . "Direct Instruction Scaffold" is the most effective $(M=4.61)$, followed by "Discourse Facilitation Scaffold" (M=4.51) and "Design \& Organization Scaffold" $(M=4.37)$. This result is in general accord with results from the content analysis of the tutor's teaching presence, although in terms of content analysis "Discourse Facilitation" was slightly higher than "Direct Instruction."

Table 9

Survey Results on Effectiveness of Scaffolds for Teaching Presence

\begin{tabular}{llll}
\hline Scaffold type & Scaffolds & Means & Std. Error \\
\hline Scaffold for TP & Design \& Organization Scaffold & 4.37 & .753 \\
& Discourse Facilitation Scaffold & 4.51 & .599 \\
& Direct Instruction Scaffold & 4.61 & .528 \\
\hline
\end{tabular}

Table 10 shows that some typical strategies are considered most effective for the development of teaching presence, such as presenting learning tasks in a structured way, questioning, guiding, and summarizing. The interview data also shows that students were most impressed by and satisfied with strategies for guiding, questioning, timely feedback, and providing summaries, a result which is consistent with existing evidence on the impacts of online tutoring strategies (Guo, Gilbert, Jackman, Starns, Hagge, Faidley, \& Amin-Naseri, 2014; Schindler \& Burkholder, 2014).

Table 10

Most Effective Strategies for Teaching Presence

Scaffold Strategy

Release a task checklist weekly

Concern about the process of students' problem solving

Praise \& commend students' speaking, and points out the highlights

Share one's learning experiences

Propose a question to guide students to think

Explain the links between learning activities and learning objectives

Explain the deep meaning of learning content, discussion of topics.
Mean Std. Er.

$\begin{array}{ll}4.52 & .593 \\ 4.59 & .503 \\ 4.70 & .559 \\ 4.57 & .507 \\ 4.61 & .583 \\ 4.61 & .583 \\ 4.65 & .487\end{array}$


Summarize different students' point of view, identify participants'

agreements/inconsistencies

Every weekend learning summary, summary the entire topic after discussion

Focus discussion on relevant issues
$4 \cdot 57$

.507

4.78

.422

$4 \cdot 57$

.507

\section{Scaffolds for Cognitive Presence}

Survey results show (Table 11) that three types of scaffolds for cognitive presence are perceived effective with means all above 4.20. Exploration Scaffold is considered most effective (M=4.44), followed by Integration Scaffold ( $M=4.41)$, while Resolution Scaffold has the lowest mean value $(\mathrm{M}=4.28)$. This result is consistent with result from the content analysis of the students' cognitive presence (Figure 4), which validates the role of scaffolding in supporting the development of cognitive presence.

Table 11

Survey Results on Effectiveness of Scaffolds for Cognitive Presence

\begin{tabular}{llll}
\hline Scaffold type & Scaffolds & Means & Std. Error \\
\hline Scaffold for CP & Exploration Scaffold & 4.44 & .606 \\
& Integration Scaffold & 4.41 & .624 \\
& Resolution Scaffold & 4.28 & .645 \\
\hline
\end{tabular}

Table 12 shows that two types of strategies for cognitive presence are the most welcomed by adult students. Students preferred strategies with case studies, especially case studies related to their own practical experiences. Strategies of timely reflection are also considered most effective, especially reflections relating to their own practical experience. Students' preference for these two strategies fully embodies the characteristics of adult distance learners.

Table 12

Most Effective Strategies for Cognitive Presence

\begin{tabular}{lcc} 
Scaffold strategy & Mean & Std. Er. \\
\hline $\begin{array}{l}\text { Encourage and guide students to think by connecting with their own } \\
\text { practice }\end{array}$ & 4.57 & .590 \\
Reflection on learning every weekend / end of each module & 4.57 & .507 \\
Reflections at the end of the course & 4.48 & .593 \\
Provide case, guide the analysis and comparison of the case & 4.52 & .511 \\
Share practical cases related & 4.43 & .590
\end{tabular}

However, some strategies in relation to Resolution Scaffold, such as "Peer assessment" and "Group collaborative design and product works," are not considered as effective as the researchers had 
expected. It's interesting that in interviews all students called for more activities of problem solving and resolution, whilst they also commented on the difficulties of group collaboration. Interview data shows that the reason may lie in the reluctance of adult learners to spend too much time on collaboration. Although the interviewees all expressed their appreciation of such strategies, they also expressed that collaborative learning, especially working on collaborative projects, was more time-consuming and they were too busy to spend enough time on it.

\section{Reflection and Refinement}

\section{Designing Principles for Social Presence}

The goal of social presence is to develop a supportive learning environment, in which students will feel comfortable and safe and be able to express their ideas without prejudice (Garrison et al., 2000). This study found that as long as a high degree of social presence is established in the Initial Phase of a learning experience, scaffolds for social presence can be withdrawn gradually and especially after the Mid-phase of a program. Learners are often able to create and shape relationships as part of their participation within the emerging community (Garrison et al., 2000). Furthermore, tutors should be careful not to be always the center of the online discussion and should leave space for learners to manage their own dialogues (Harris, 2003). The results of this study confirm these findings and observations and shows that students are able to promote the development of social presence even after the designed scaffolds have faded.

More attention should be paid to the newly-added dimension, Environment Acclimation Scaffold, which was also highly recognized by students in this study. Distance learners, partly because of their learning context, tend to encounter a lot of technical problems in the initial phase (Anderson, 2008). If not solved in a timely manner, these technical problems can result in a great deal of disturbance and delay to students' participation and development of social presence. Since it is not possible for the distance tutor to always foresee these technical problems, it's important for the tutor to keep a close eye on this aspect of the course and adapt strategies in relation to Environment Acclimation Scaffolding.

\section{Designing Principles for Teaching Presence}

Scaffolds for teaching presence are designed to support and promote teaching presence of the tutor as well as the students. Survey and interview results from this study show that teaching presence plays an important role in students' satisfaction with the online course, which is consistent with existing research on the topic (Joo et al., 2011; Lee, 2014). It's important to provide a proper level of scaffolding for teaching presence in the Initial Phase when students are negotiating the scope of the subject matter. Two purposes should be emphasized when scaffolding the development of teaching presence in the Initial Phase of a program. The first is to establish students' trust in the academic credibility of the tutor. Typical strategies such as a self-introduction video are helpful (Anderson, 2008). Second is role modeling of the discourse among students. Although greater levels of participation, motivation and student satisfaction can occur when discussion groups are led by student moderators, students will not normally have the necessary skills to undertake successful 
moderation of class discussion (Rourke \& Anderson, 2002; Rouke \& Kanuka, 2007). Therefore, scaffolding by the tutor is critical for development of teaching presence in the initial phase.

Results also show that a low degree of teaching presence of the tutor in the Last Phase had no obvious effects on students' presence, while the tutor's low teaching presence in the Mid-phase might have caused a corresponding drop in social presence, teaching presence and cognitive presence of students. Likewise, students exhibited higher degrees of social, teaching and cognitive presence when the tutor's teaching presence increased. These results support other studies to some degree in suggesting that teaching presence has a significant effect on both social presence and cognitive presence (Garrison, 2011; Garrison et al., 2010; Joo et al., 2011; Shea \& Bidjerano, 2009; Szeto, 2015). Moreover, the finding reveals the important role of high-intensity teaching presence in the Mid-phase, where it is much more important than that in the other two phases.

According to the tutor's reflection, there may be two reasons for the unusual decline of teaching presence in Module 4. The first is the heavy workload of the tutor, which kept her occupied with other work during Module 4. Second, and more importantly, it's possible that the tutor assumed that as the students had performed well in the past 3 modules, they might be able to continue their good discourse and interactions in the absence of scaffolding to a degree. Figure 6 shows that actually the tutor didn't withdraw the scaffolding intensity on Direct Instruction or Design \& Organization, but mainly withdrew the intensity of scaffolding on Discourse Facilitation, which is more time-consuming for the tutor. This finding is interesting in view of arguments in relation to the importance of teaching presence, especially Direct Instruction or Discourse Facilitation (Anderson, 2008; Anderson et al., 2001; Salmon, 2000). This study seemed to support the view of Salmon and others that in online learning the tutor would play a more important role in facilitating and moderating than in in direct instruction (Salmon, 2000, 2004). The results also verify the notion that it cannot be assumed that students naturally possess successful moderation skills for class discussion, and that critical discourse would not necessarily happen without facilitating and scaffolding from the tutor (Anderson, 2008; Guldberg \& Pilkington, 2007; Rourke \& Kanuka, 2007).

Existing research has already emphasized the importance of direct instruction for teaching presence (Anderson et al., 2001). Both the results from the content analysis and the survey show that Direct Instruction did play an important role in students' satisfaction with teaching presence. Meanwhile, as designed, the tutor largely withdrew the scaffolding intensity of Direct instruction in the Final Phase, aiming to ease control of the class and leave more space for students to evolve their discourse and to develop high levels of critical thinking skills (Harris, 2003). As expected, no decline of students' presence occurred, whilst students exhibited high degrees of social presence and cognitive presence. This finding indicated that although the scaffolding for Direct Instruction needed to be kept high in the Mid-phase, it should fade in the Final Phase to leave control of the class to students.

\section{Designing Principles for Cognitive Presence}

In this study, students demonstrated a high level of cognitive presence, and gave a high recognition to scaffolds for cognitive presence. Variation of students' cognitive presence matches best with the design of varied-intensity scaffolds for cognitive presence. Students started from an adequate value of cognitive presence at the Initial Phase and increased gradually to a peak value at the Final Phase. The 
strongest intensity of scaffolding for cognitive presence should be provided in the Final Phase. As Salmon (2004) has pointed out, in the last stage of an online course, "participants look for more benefits from the system; they want help in achieving their own goals, in exploring how to integrate their online experiences into other forms of learning and in transferring and applying their learning."

\section{Refinement to the First Iteration of Scaffolding}

Results of the survey and content analysis from this study indicated that the design of "Group Cohesion Scaffold" for social presence was not as good as expected. Although many studies have proved that online collaborative learning is even more difficult than face-to-face collaboration (Chen, Wu, Yang, \& Tsou, 2008), this study showed that the researchers still underestimated the difficulty of online collaboration in the first iteration. More scaffolds will need to be designed for group cohesion in the second iteration of the study with Chinese learners, such as more detailed descriptions of roles and responsibilities for groups.

According to the Practical Inquiry Model (PIM), the lowest level of cognitive presence is Triggering Event (Garrison et al., 2001), which is the easiest one to achieve. However, in the first iteration of this study, when no targeted scaffolds were designed for Triggering Event, it resulted in the lowest value of Triggering Event in students' cognitive presence. The other 3 levels, which were considered to be higher levels in critical thinking and more difficult to achieve according to PIM, exhibited higher values instead. This result indicated that targeted scaffold design was always necessary and critical. No matter how low-level the learning objective was, learning objectives would not necessarily be achieved if no targeted scaffolds are designed and provided purposefully. Hence, a refinement will be made in the second iteration of this design-based research study to purposefully design scaffolds for Triggering Event for cognitive presence.

Regarding the survey result, the students' perception of scaffolds for Resolution in Cognitive Presence was fairly good. However, the content analysis result showed that students' Resolution value was fairly low. This finding was not surprising, since previous studies also found that it was difficult to achieve the level of Resolution (Kanuka, Rourke, \& Laflamme, 2007; Rourke \& Kanuka, 2009). According to the theory of scaffolding (Azevedo, Cromley, \& Seibert, 2004), the more difficult the objective is for students, the more and stronger scaffolding should be provided for students. Thus, in the second iteration of this study, the highest intensity of scaffolding should be designed to support the highest level of cognitive presence. In interviews students reported the difficulties of online collaboration and working on group projects, which is widely acknowledged (Chen et al., 2008). Hence more scaffolding strategies will need to be designed to support online collaboration and group work, in order to better support Resolution.

\section{Conclusion}

This study underscores both the critical role of the tutor in online learning and the importance of scaffolding for online tutoring. Its findings support existing research, which indicated that students do not normally possess all the skills necessary to engage in class discussions and in productive discourse or moderation therein (Anderson, 2008; Anderson et al., 2001). The study demonstrates that students' social, teaching, and cognitive presence is enhanced by the design and implementation of 
suitable and appropriate levels of scaffolds, some of which are particularly critical at different phases of a course.

Although existing research has identified numerous strategies for scaffolding online tutoring (Guo et al., 2014; Lentell, 2003; Schindler \& Burkholder, 2014), few of them have considered variation in scaffolding as an important factor. This study sheds light on varying learning and teaching scaffolds to support the hypothesis that different levels of presence should be emphasized at different phases of a course. It also suggests that different types of scaffolds for different types of presence should be emphasized or withdrawn separately at different stages. For example, Discourse Facilitation should be emphasized as part of teaching presence in the Mid-phase, while Direct Instruction needs to be faded in the end.

This study also supports the claim that adaptive scaffolding is better than fixed scaffolding (Azevedo, Cromley, Moos, Greence, \& Winters, 2011; Azevedo et al., 2004; Feng, 2012). Also, tutors should keep a close eye on the learning process and adjust their scaffolding as and when the situation demands such adjustments. Most importantly, tutors should learn to be good judges of when to guide, when to facilitate, when to question, and when to provide direct instruction. This is consistent with existing research, which suggests that expert online tutors need to adopt both proactive and reactive strategies (Wong, Chin, Tan, \& Liu, 2010).

This first iteration of an exploratory study carried out in an exclusively Chinese educational context offers some interesting insights into the relationships between scaffolding and presences, and into the value of using the Community of Inquiry framework to scaffold online tutoring in such a context. In the second iteration of this design-based research study, more rigorous data gathering strategies will need to be adopted to investigate the statistical significance of the correlations between scaffolding and presence.

\section{References}

Amiel, T., \& Reeves, T. C. (2008). Design-based research and educational technology: Rethinking technology and the research agenda. Educational Technology \& Society, 11(4), 29-40.

Anderson, T. (2008). The theory and practice of online learning (2nd Edition). Edmonton, Alberta: Athabasca University Press.

Anderson, T., Rourke, L., Garrison, D. R., \& Archer, W. (2001). Assessing teaching presence in a computer conferencing context. Journal of Asynchronous Learning Networks, 5(2), 1--17.

Anderson, T., \& Shattuck, J. (2012). Design-based research: A decade of progress in education research? Educational Researcher, 41(1), 16-25.

Annand, D. (2011). Social presence within the community of inquiry framework. International Review of Research in Open \& Distance Learning, 12(5), 40-56. 
Azevedo, R. (2005). Using hypermedia as a metacognitive tool for enhancing student learning? the role of self-regulated learning. Educational Psychologist, 4O(4), 199-209.

Azevedo, R., Cromley, J.G., Moos, D.C., Greence, J.A., \& Winters, F.I. (2011). Adaptive content and process scaffolding: A key to facilitating students' self-regulated learning with hypermedia. Psychological Test and Assessment Modeling, 53(1), 106-140.

Azevedo, R., Cromley, J.G., \& Seibert, D. (2004). Does adaptive scaffolding facilitate students' ability to regulate their learning with hypermedia? Contemporary Educational Psychology, 29, 344370 .

Barker, P. (2002). On being an online tutor. Innovations in Education and Teaching International, $39(1), 3-13$.

Bennett, S. \& Marsh, D. (2002). Are we expecting online tutors to run before they can walk? Innovations in Education \& Teaching International, 39(1), 14-20.

Berge, Z.L. (1995). Facilitating computer conferencing: Recommendations from the field. Educational Technology, 35(1), 22-30.

Branon, R. F., \& Essex, C. (2001). Synchronous and asynchronous communication tools in distance education. Techtrends, 45(1), 36-36.

Chen, C. C., Wu, J., Yang, S. C., \& Tsou, H.-Y. (2008). Importance of diversified leadership roles in improving team effectiveness in a virtual collaboration learning environment. Educational Technology \& Society, 11(1), 304-321.

Chism, N. V. N. (1998). Developing a philosophy of teaching statement. Essays on Teaching Excellence, 9(3), 1-2.

Daele, A., \& Docq, F. (2002, May). Le tuteur en ligne, quelles conditions d'efficacité dans un dispositive d'apprentissage collaboratif à distance? [The online tutor, what conditions of effectiveness in a mechanism of collaborative distance learning?]

Proceedings of the AIPU Conference, Louvain-la-Neuve. Retrieved from https://search.yahoo.com/yhs/search?p=Le+tuteur+en+ligne\%2C+quelles+conditions+d\%E2\% 80\%99efficacit\%C3\%A9+dans+un+dispositive+d\%E2\%80\%99apprentissage+collaboratif $+\% \mathrm{C}_{3}$ \%Ao+distance\%3F\&ei=UTF-8\&hspart=mozilla\&hsimp=yhs-001

Denis, B. (2003). Quels ro^ les et quelle formation pour les tuteurs intervenant dans des dispositifs de formation à distance? [What are the roles and training for tutors involved in distance learning devices?]. Distances et savoirs, 1(1), 19-46.

Denis, B., Watland, P., Pirotte, S., \& Verday, N. (2004, June). Roles and competencies of the e-tutor. In Networked learning 2004: A research based conference on networked learning and lifelong learning: Proceedings of the fourth international conference, Lancaster. 
Dennis, A. R., \& Williams, M. L. (2005). A meta-analysis of group side effects in electronic brainstorming: More heads are better than one. International Journal of e-Collaboration (IJeC), 1(1), 24-42.

Dillenbourg, P. (2002). Over-scripting CSCL: The risks of blending collaborative learning with instructional design. Three worlds of CSCL. Can we support CSCL? 61-91.

Dixon, J., Crooks, H., \& Henry, K. (2006). Breaking the ice: Supporting collaboration and the development of community online. Canadian Journal of Learning and Technology/La revue canadienne de l'apprentissage et de la technologie, 32(2).

Feng, X. (2012). Scaffolding facilitates inter-school collaborative learning: A case study in China. Journal of Educational Technology Development and Exchange, 5(1), 45-62.

Garrison, D. R. (2003). Cognitive presence for effective asynchronous online learning: The role of reflective inquiry, self-direction and metacognition. Elements of Quality Online Education: Practice and Direction, 4, 47-58.

Garrison, D. R. (2011). E-learning in the 21st century: A framework for research and practice [Second edition]. New York: Routledge.

Garrison, D.R., Anderson, T., \& Archer, W. (2000). Critical inquiry in a text-based environment: Computer conferencing in higher education. The Internet and Higher Education, 2(2-3), 87-105.

Garrison, D. R., Anderson, T., \& Archer, W. (2001). Critical thinking, cognitive presence, and computer conferencing in distance education. American Journal of Distance Education, 15(1), 7-23.

Garrison, D. R., Anderson, T., \& Archer, W. (2003). A theory of critical inquiry in online distance education. Handbook of distance education, 1, 113-127.

Garrison, D.R., Anderson, T., \& Archer, W. (2010). The first decade of the community of inquiry framework: a retrospective. The Internet and Higher Education, 13, 5-9.

Garrison, D.R., \& Arbaugh, J.B. (2007). Researching the community of inquiry framework: Review, issues, and future directions. The Internet and Higher Education, 1O(3), 157-172.

Goga, M. (2012). Training e-tutors in Romania: Validating the theory. Proceedings of the 11th European Conference on e-Learning, 174.

Guldberg, K., \& Pilkington, R.M. (2007). Tutor roles in facilitating reflection on practice through online discussion. Educational Technology \& Society, 1O(1), $61-72$.

Guo, E., Gilbert, S., Jackman, J., Starns, G., Hagge, M., Faidley, L., \& Amin-Naseri, M. (2014, June). Statics tutor: Free body diagram tutor for problem framing. In S. Trausan-Matu, K. E. Boyer, M. Crosby, \& K. Panourgia (Eds.) Intelligent Tutoring Systems: Proceedings of the 12th 
International Conference, ITS 2014, (pp. 448-455). Cham, Switzerland: Springer International Publishing. doi: 10.1007/978-3-319-07221-0

Harris, B. (2003). Transitioning to online facilitation. In T. Dewar (Ed.) Keyboard voices: Reflections on online facilitation and community building. Victoria, British Columbia: Royal Roads University.

Joo, Y. J., Lim, K. Y., \& Kim, E. K. (2011). Online university students' satisfaction and persistence: Examining perceived level of presence, usefulness and ease of use as predictors in a structural model. Computers \& Education, 57(2), 1654-1664.

Junus, K., Sadita, L., \& Suhartanto, H. (2014). Social, cognitive, teaching, and metacognitive presence in general and focus group discussion: Case study in blended e-learning Linear Algebra class. 2014 IEEE Frontiers in Education Conference (FIE) [Proceedings](pp.1-6). IEEE Computer Society.

Kanuka, H., Rourke, L., \& Laflamme, E. (2007). The influence of instructional methods on the quality of online discussion. British Journal of Educational Technology, 38(2), 260-271.

Ke, F. (2010). Examining online teaching, cognitive, and social presence for adult students. Computers \& Education, 55(2), 808-820.

Laurillard, D. (2002). Rethinking university teaching: A conversational framework for the effective use of learning technologies [2nd edition]. London: Routledge/Falmer.

Lee, S.M. (2014). The relationships between higher order thinking skills, cognitive density, and social presence in online learning. The Internet and Higher Education, 21, 41-52.

Lentell, H. (2003). The importance of the tutor in open and distance learning. In A. Tait and R. Mills (Eds), Rethinking learner support in distance education: Change and continuity in an international context, (pp. 64-76). London: Routledge/Falmer.

Maddix, M. A. (2012). Developing online learning communities. In M.A. Maddix, J.R. Estep, \& M.E. Lowe (Eds.), Best Practices of Online Education: A Guide for Christian Higher Education, (pp. 31-40). Charlotte, NC: Information Age Publishing.

McConnell, D. (1994). Managing open learning in computer supported collaborative learning environments. Studies in Higher Education, 19(3), 341-358.

Mercer, N. (1995). The guided construction of knowledge: Talk amongst teachers and learners. Clevedon, UK: Multilingual Matters Ltd.

Pilkington, R. M., \& Walker, S. A. (2003). Facilitating debate in networked learning: Reflecting on online synchronous discussion in higher education. Instructional Science, 31, 41-63. 
Reeves, T. C. (2006). Design research from a technology perspective. In J. van den Akker, K. Gravemeijer, S. McKenney, \& N. Nieveen (Eds.), Educational Design Research (pp. 52-66). New York: Routledge.

Rourke, L., \& Anderson, T. (2002). An investigation of collaborative problem solving using different communications modes in distance education. In EdMedia: World Conference on Educational Media and Technology (Vol. 2002, No. 1, pp. 48-50).

Rourke, L, Anderson, T., Garrison, D.R., \& Archer, W. (2001). Assessing social presence in asynchronous text based computer conferencing. Journal of Distance Education, 14(2), 50-71.

Rourke, L., \& Kanuka, H. (2007). Barriers to online critical discourse. Computer-Supported Collaborative Learning, 2, 105-126.

Rourke, L., \& Kanuka, H. (2009). Learning in communities of inquiry: A review of the literature. Journal of Distance Education, 23(1), 19-48.

Ryan, R. M., \& Deci, E. L. (2000). Self-determination theory and the facilitation of intrinsic motivation, social development, and well-being. American psychologist, 55(1), 68.

Salmon, G. (2000). E-moderating: The key to teaching and learning online. London: Kogan Page.

Salmon, G. (2002). E-tivities: The key to active online learning. London: Routledge Falmer.

Salmon, G. (2003). E-moderating: The key to teaching and learning online (2nd ed.). London and New York: Routledge Falmer.

Salmon, G. (2004). E-moderating: The key to teaching and learning online. London and New York: Routledge Falmer.

Schellens, T., Van Keer, H., \& Valcke, M. (2005). The impact of role assignment on knowledge construction in asynchronous discussion groups: A multilevel analysis. Small Group Research, 36(6), 704-745.

Schindler, L.A. \& Burkholder, G.J. (2014). Instructional design and facilitation approaches that promote critical thinking in asynchronous online discussions: A review of the literature. Higher Learning Research Communications, 4(4), pp. 11-29.

Shea, P., \& Bidjerano, T. (2009). Community of inquiry as a theoretical framework to foster "epistemic engagement" and "cognitive presence" in online education. Computers \& Education, 52(3), 543-553.

Shea, P., Hayes, S., Vickers, J., Gozza-Cohen, M., Uzuner, S., Mehta, R., Valchova, A., \& Rangan, P. (2010). A re-examination of the community of inquiry framework: social network and content analysis. Internet \& Higher Education, 13(1-2), 10-21.

Simpson, O. (2002). Supporting students in open and distance learning ( $2^{\text {nd }}$ ed.). London: Kogan Page. 
Swan, K., \& Ice, P. (2010). The community of inquiry framework ten years later: Introduction to the special issue. The Internet \& Higher Education, 13, 1-4.

Szeto, E. (2015). Community of Inquiry as an instructional approach: What effects of teaching, social and cognitive presences are there in blended synchronous learning and teaching? Computers \& Education, 81, 191-201.

Tu, C. H., \& McIsaac, M. (2002). The relationship of social presence and interaction in online classes. The American Journal of Distance Education, 16(3), 131-150.

Wang, F., \& Hannafin, M. J. (2005). Design-based research and technology-enhanced learning environments. Educational Technology Research \& Development, 53(4), 5-23.

Wishart, C., \& Guy, R. (2009). Analyzing responses, moves, and roles in online discussions. Interdisciplinary Journal of E-Learning and Learning Objects, 5(1), 129-144.

Wong, L.-H., Chin, C.-K., Tan, C.-L., \& Liu, M. (2010). Students' personal and social meaning making in a Chinese idiom mobile learning environment. Educational Technology \& Society, 13(4), $15-26$.

Zhang, L., \& Yao, L. (2013). Research on ecological governance of online learning forum. e-Education Research, 7, 22-26,52 


\title{
Appendix A
}

\section{Online Tutoring Scaffolding Strategy Survey Instrument}

\author{
A.1. Social Presence
}

A.1.1. Group Cohesion Scaffold

1. Welcome letter

2. Online ice-breaking activity

3. The first video-conferencing for ice-breaking

4. Team building: Design team slogan, choose the monitor and vice monitor

5. Call the names of students kindly

A.1.2. Emotional Expression Scaffold

6. Use friendly language and emotional words (respect, apologies, happy, etc.), humorous utterance, graphic symbols, network language and so on

7. Express own preferences, attitudes, etc.

A.1.3. Open Communication Scaffold

8. Thank students for their contributions, share and suggestions.

9. Publish online discussion etiquette

10. Weekly appreciation/weekly star, pose the outstanding student list and their contribution

11. Present details or examples of life outside of class

A.1.4. Environment Acclimation Scaffold

12. Get familiar with the course platform

13. Answer students' questions about technology platform or other questions

14. Inform the process of problem solving and efforts

\section{A.2. Teaching Presence}

\section{A.2.1. Design \& Organization Scaffold}

15. Release a task checklist weekly

16. Establish arrangement of teaching in the "learning calendar"

17. Release a task reminder weekly

18. Use Internet messaging and e-mail to alert courses process

19. Inform of other students' learning progress

20. Express the expectations for students

\section{A.2.2. Discourse Facilitation Scaffold}

21. Concern about the process of students' problem solving

22. Give formative agreement for students' ideas.

23. Praise \& commend students' speaking, and point out the highlights 
24. Cite students' posts

25. Give reference format and examples

26. Use messages in platform to remind and encourage students to participate in

27. Use repeat and summarize to confirm the views expressed by students

28. Propose a question to guide students to think

29. Focus discussion on relevant issues

30. Use guided questions

31. Summarize and comment a student's view

32. Summarize different students' point of view, identify participants' agreements/inconsistencies

33. Every weekend learning summary, summary the entire topic after discussion

\section{A.2.3. Direct Instruction Scaffold}

34. Explain the links between learning activities and learning objectives

35. Share ones learning experiences

36. Explain the deep meaning of learning content, discussion of topics.

\section{A.3. Cognitive Presence}

\section{A.3.1. Exploration Scaffold}

37. Provide case, guide the analysis and comparison of the case

38. Share information or document

39. Encourage and guide students to think by connecting their own practice

40. Share practical cases related

41. Peer assessment

\section{A.3.2. Integration Scaffold}

42. Reflect on learning every weekend / end of each module

43. Reflect at the end of the course

44. Videoconference after courses to reflect, summarize and share

45. Group Collaboration to summarize topic posts of each module

\section{A.3.3. Resolution Scaffold}

46. Debate

47. Case analysis

48. Evaluate the case

49. Group collaborative design and product works

\section{Athabasca \\ University}

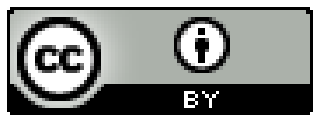

